\title{
Article \\ Mixed Convection of Silica-Molybdenum Disulphide/Water Hybrid Nanoliquid over a Rough Sphere
}

\author{
Prabhugouda M. Patil ${ }^{1}$, Hadapad F. Shankar ${ }^{1}$ and Mikhail A. Sheremet ${ }^{2, *}$ \\ 1 Department of Mathematics, Karnatak University, Pavate Nagar, Dharwad 580003, India; \\ pmpatil@kud.ac.in (P.M.P.); shankarhf@kud.ac.in (H.F.S.) \\ 2 Laboratory on Convective Heat and Mass Transfer, Tomsk State University, 634050 Tomsk, Russia \\ * Correspondence: sheremet@math.tsu.ru; Tel.: +7-3822-529740
}

Citation: Patil, P.M.; Shankar, H.F.; Sheremet, M.A. Mixed Convection of Silica-Molybdenum Disulphide/ Water Hybrid Nanoliquid over a Rough Sphere. Symmetry 2021, 13, 236. https://doi.org/10.3390/ sym13020236

Academic Editor: Rahmat Ellahi Received: 27 December 2020

Accepted: 23 January 2021

Published: 31 January 202

Publisher's Note: MDPI stays neutral with regard to jurisdictional claims in published maps and institutional affiliations.

Copyright: () 2021 by the authors. Licensee MDPI, Basel, Switzerland. This article is an open access article distributed under the terms and conditions of the Creative Commons Attribution (CC BY) license (https:// creativecommons.org/licenses/by/ $4.0 /)$.
Abstract: A steady combined convective motion over a rough sphere with hybrid nanoparticles is analyzed. We have considered silica $\left(\mathrm{SiO}_{2}\right)$ and molybdenum disulphide $\left(\mathrm{MoS}_{2}\right)$ nanoadditives which are added in $\mathrm{H}_{2} \mathrm{O}$ to form $\mathrm{MoS}_{2}-\mathrm{SiO}_{2} / \mathrm{H}_{2} \mathrm{O}$ hybrid nanoliquid. The partial differential equations describing the boundary layer flow characteristics are reduced into non-dimensional form with appropriate non-similar reduction. It should be noted that the governing equations have been written using the conservation laws of mass, momentum and energy. These considered equations allow simulating the analyzed phenomenon using numerical techniques. Implicit finite difference approximation and technique of Quasilinearization are utilized to work out the dimensionless control equations. The influence of various physical characteristics included in this challenge, such as the velocity fields and temperature patterns, is investigated. The study of border gradients is performed, which deals with the skin friction and energy transport strength. The plots of computational outcomes are considered, which ascertain that velocity distribution reduces, whilst coefficient of friction at the surface, energy transport strength and temperature distribution augment for enhancing values of hybrid nanofluid. For enhancing magnitude of combined convection parameter, dimensionless velocity distribution, surface drag coefficient and energy transport strength enhance, while temperature distribution diminishes. High impact of hybrid nanofluid on energy transport strength and the surface friction compared to the host liquid and mono nanofluid in presence/absence of surface roughness is shown. Velocity distribution enhances for rising values of velocity ratio parameter. Enhancing values of frequency parameter rise the friction at the surface and energy transport strength. It is also examined that the hybrid nanofluid has a maximum temperature for the blade-shaped nanoparticles and has a low temperature for the spherical-shaped nanoparticles.

Keywords: sphere; surface roughness; hybrid nanofluid; mixed convection; quasilinearization technique

\section{Introduction}

The transport behavior of nanofluids can be described using, for example, Buongiorno's model [1] and Tiwari and Das approach [2]. In Buongiorno's approach, the nanoparticles' slip velocity is not zero considering seven possible slip phenomena including thermophoresis, Magnus effect, inertia, Brownian motion, diffusiophoresis, gravity and fluid drainage. Tiwari and Das model [2] can be considered as an effective model with formulae for heat conductivity and dynamic viscosity that are greater than in the case of regular liquids. Therefore, Tiwari and Das approach can be considered as a homogeneous model which is different from Buongiorno's model.

Nanofluid is a combination of host fluid and nano-sized solid particles [3]. Scientists are in search of better type of liquid in order to enhance the thermal efficiency of different engineering systems. Taking into account such investigation, the hybrid nanofluid as a combination of base liquid and several different types of nanoparticles, can have high thermal conductivity compared to mono nanofluid and hybrid nanofluids can be considered 
as the advanced forms of nanofluid. Hybrid nanofluids have heat transfer applications in numerous engineering fields such as, manufacturing, naval structures, transportation, acoustics, defense, micro fluidics, medical etc. [4-6]. Thus, Waini et al. [7] have analyzed the combined convection hybrid nanoliquid circulation about a vertical border and their results reveal that the energy transport strength diminishes in shrinking case. In the work of Dinarvand et al. [8], hybrid nanofluid flow past a wedge by considering titanium and copper nanoparticles has been analyzed. Rostami et al. [5] have scrutinized the combined convection of a hybrid silica-alumina nanofluid and their results ascertain that the hybrid nanofluid has high energy transport strength than the base fluid. Moreover, many other researchers have worked by considering the different combination of nanoparticles for hybrid nanofluids such as, $\mathrm{Ag}-\mathrm{TiO}_{2}, \mathrm{CuO}-\mathrm{MgO}, \mathrm{Cu}-\mathrm{Al}_{2} \mathrm{O}_{3}$ and $\mathrm{MWCNTs}-\mathrm{Fe}_{2} \mathrm{O}_{4}$-SWCNTs, etc. [9-13]. Since, many authors such as Maraj et al. [14], Ghadikolaei et al. [15], Khan et al. [16], etc., have studied the water containing Molybdenum disulphide and Silica nanoparticles, considering the either of one or both nanoparticles. Chemical attributes of molybdenum disulfide including capabilities of lubrication, heat conductivity and thermal capacitance are employed in various engineering systems [17]. In addition, Silicon oxide (silica) is widely applied in energy transport applications and it can be successfully use as nano-inclusions [18]. The work of these authors has motivated us to perform the present research and therefore, we have investigated the current problem.

Some kinds of nanoadditives have been employed by some scientists in theoretical and experimental researches. Among the various types of nanoadditives, one of them is known as molybdenum disulfide nanoadditives. Such nanoadditives are rarely employed in the papers particularly in theoretical researches. $\mathrm{MoS}_{2}$ is characterized by large band gaps structure which is related to the structure of grapheme and as a result, $\mathrm{MoS}_{2}$ is employed in different engineering systems [19-26]. Moreover, chemical attributes of $\mathrm{MoS}_{2}$ can be applied in various mechanical systems [23]. $\mathrm{MoS}_{2}$ particles have been coated with copper to improve their combination with the copper particles for the sintering [24]. Further, silicon is widely spread element on earth after oxygen [25]. Silicon has very useful attributes that illustrates many different applications of this element in various fields. Silicon chips have essentially changed different technical systems including electronics, space and aviation industry, and others. Silicon is used in photovoltaic panels that characterize the high efficiency and suitability. Silicon oxide (silica) is widely employed in energy transport applications and it can be successfully applied as a nanoadditive [18].

In many branches of science and technology, the notion of mixed convection flow can be applied. Correspondingly, combined convection flows play a crucial role in the operation of thermal processing, such as in heated or cooled enclosures and electrical power supply, ventilation and air conditioning systems in atmospheric and ocean circulation, electronic equipment and thermal distribution in buildings [27-29]. In particular, owing to its prevalence in engineering fields, the combined convection flow around the sphere has been stimulated by several researchers. The examination of heat transport in combined convective motion over a sphere helps in polymer and fiber industries. Different investigators have studied a combined convective boundary layer motion over a sphere. Combined convective motion around a solid sphere was studied by Salleh et al. [30], taking Newtonian warming into the consideration and their outcomes exhibit that the dimensionless velocity and temperature patters can be reduced with Pr. In addition, Rashad et al. [31] examined the combined convective motion past a sphere and authors have ascertained that the chemical effects are noticeable for energy transport strength. Further, many researchers also analyzed the combined convective water boundary layer flow over a sphere [32,33].

Many scientists have also examined the hybrid nanofluid circulation over different geometries. Recently, Waini et al. [34] have scrutinized combined convective motion with $\mathrm{Cu}-\mathrm{Al}_{2} \mathrm{O}_{3} / \mathrm{H}_{2} \mathrm{O}$ nanoliquid past a surface and their results reveal that the surface drag coefficient lessens for opposing buoyancy flow, while it boosts for assisting buoyancy flow. Further, Muhammad et al. [35] have analyzed combined convection over a curved surface with MWCNT- $\mathrm{Cu} / \mathrm{H}_{2} \mathrm{O}$ hybrid nanofluid and the obtained outcomes ascertain that the 
fluid velocity enhances for combined convection parameter. Bognar et al. [36] have studied the nanofluid flow over a uniformly moving plate considering different nanoparticles and their outcomes reveal that the values of velocity and temperature are greater for alumina nanoparticles compared to titania and magnetite particles. In addition, Bognar and Hriczo [37] have studied the ferrofluids behavior over a flat sheet under the variable magnetic field influence. They have revealed that a rise of the ferromagnetic parameter characterizes the velocity reduction and temperature augmentation. Many researchers have also worked on the combination of silica and molybdenum nanoparticles by considering various base fluids such as water, ethylene glycol, etc. [38,39].

The one feature that tests micro-irregularities presented in the surface texture, is the surface roughness. The roughness analysis was initiated by Nikuradse [40] where he explored the roughness effects on surface drag coefficient. Owen and Thompson [41] have examined the influence of roughness on energy transport strength, while Dawson and Trass [42] have investigated its influence on Sherwood number. Sedahmed and Shemilt [43] have examined the forced convection behavior owing to the border roughness. Patil et al. [44] have investigated the nanosuspension combined convection motion over a rough sphere and their outcome reveals that with suitable choice of roughness and combined convection parameter the point of separation can be delayed. In addition, Patil et al. [45] have analyzed nanoliquid motion about a moving plate and their outcome shows that the friction at the surface enhances.

Taking into account this brief literature review, it can be found that investigation of the combined convective flow of molybdenum silica/water hybrid nanofluid about a rough sphere has not been studied earlier. The novelty of the present analysis includes the following points:

- combined convective flow over a rough sphere;

- impact of molybdenum-silica/water hybrid nanofluid on flow structures and heat patterns;

- $\quad$ effect of surface roughness on hydro- and thermodynamics.

The modeled governing equations and their boundary constraints are affected to the appropriate non-similar reduction. Further, the obtained relations are attempted for solution transformations by employing the method of Quasilinearization and the implicit finite difference approximation $[44,45]$.

\section{Mathematical Analysis}

Herein, we investigate the viscous, laminar, incompressible combined convection motion around a sphere. Here $R$ is the sphere size. Let $T_{w}$ and $T_{\infty}$ be the temperature at the border and away from the surface. The geometry and the configuration of the flow system are schematically presented in Figure 1. Here $x$ is the curvilinear coordinate over the sphere border, while coordinate $y$ is perpendicular it. The section $r(x)$ explains the contour of the considered object.

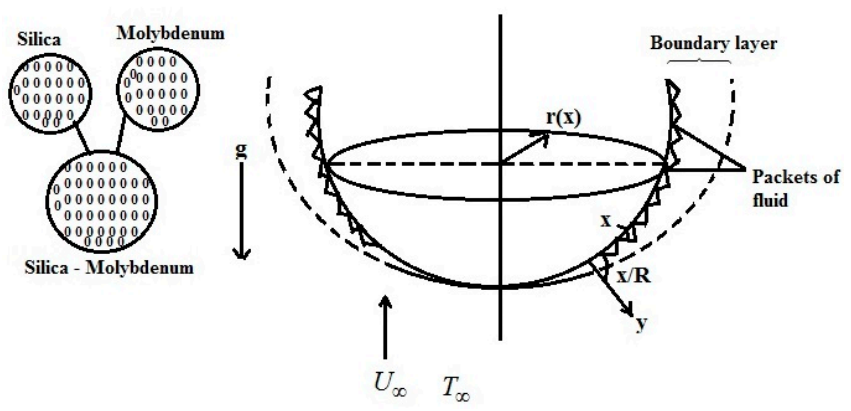

Figure 1. Engineering sketch and mathematical conditions. 
The surface roughness is modeled in terms of large frequency and low amplitude sinusoidal waves. The control equations representing the hybrid nanosuspension flow variations are $[2,7,42-45]$ :

$$
\begin{gathered}
\frac{\partial(r u)}{\partial x}+\frac{\partial(r v)}{\partial y}=0 \\
u \frac{\partial u}{\partial x}+v \frac{\partial u}{\partial y}=\frac{\mu_{h n f}}{\rho_{h n f}} \frac{\partial^{2} u}{\partial y^{2}}+\frac{(\rho \beta)_{h n f}}{\rho_{h n f}} g\left(T-T_{\infty}\right) \sin \left(\frac{x}{R}\right)+U_{e} \frac{d U_{e}}{d x} \\
u \frac{\partial T}{\partial x}+v \frac{\partial T}{\partial y}=\frac{k_{h n f}}{\left(\rho c_{p}\right)_{h n f}} \frac{\partial^{2} T}{\partial y^{2}}
\end{gathered}
$$

Prescribed border constraints are

$$
\left.\begin{array}{c}
\text { At } y=0: u=U_{w}(x)=U_{0} \alpha \sin \left(\frac{n x}{R}\right), v=0, T=T_{W} \\
\text { As } y \rightarrow \infty: u \rightarrow U_{e}(x)=\frac{3}{2} U_{\infty} \sin \left(\frac{x}{R}\right), \quad T \rightarrow T_{\infty}
\end{array}\right\}
$$

Here, $u$ indicates the nanosuspension velocity component over $x$ coordinate, $v$ indicates the nanosuspension velocity component over $y$ axis and hybrid nanofluid temperature is indicated T. Further, $\rho_{h n f}, \mu_{h n f},\left(\rho c_{p}\right)_{h n f},(\rho \beta)_{h n f}$ and $k_{h n f}$ denote the density, viscosity, thermal capacitance, heat expansion coefficient and heat conductivity of the

\begin{tabular}{|c|c|c|}
\hline Properties & Nanofluid & Hybrid Nanofluid \\
\hline Dynamic viscosity & $\mu_{n f}=\frac{\mu_{f}}{\left(1-\phi_{1}\right)^{2.5}}$ & $\mu_{h n f}=\frac{\mu_{f}}{\left(1-\phi_{1}\right)^{2.5}\left(1-\phi_{2}\right)^{2.5}}$ \\
\hline Density & $\rho_{n f}=\left(1-\phi_{1}\right) \rho_{f}+\phi_{1} \rho_{s_{1}}$ & $\rho_{h n f}=\left[\phi_{2} \rho_{s_{2}}+\left(1-\phi_{2}\right)\left\{\begin{array}{c}\phi_{1} \rho_{s_{1}}+ \\
\left(1-\phi_{1}\right) \rho_{f}\end{array}\right.\right.$ \\
\hline Thermal conductivity & $k_{n f}=k_{f} \frac{k_{s_{1}}+2 k_{f}-2 \phi_{1}\left(k_{f}-k_{s_{1}}\right)}{k_{s 1}+2 k_{f}+\phi_{1}\left(k_{f}-k_{s_{1}}\right)}$ & $\begin{array}{c}k_{h n f}=k_{n f} \frac{k_{s_{2}}+2 k_{n f}-2 \phi_{2}\left(k_{n f}-k_{s_{2}}\right)}{k_{s_{2}}+2 k_{n f}+\phi_{2}\left(k_{n f}-k_{s_{2}}\right)} \\
\text { with } k_{n f}=k_{f} \frac{k_{s_{1}}+2 k_{f}-2 \phi_{1}\left(k_{f}-k_{s_{1}}\right)}{k_{s 1}+2 k_{f}+\phi_{1}\left(k_{f}-k_{s_{1}}\right)}\end{array}$ \\
\hline Thermal expansion coefficient & $(\rho \beta)_{n f}=\left(1-\phi_{1}\right)(\rho \beta)_{f}+\phi_{1}(\rho \beta)_{s_{1}}$ & 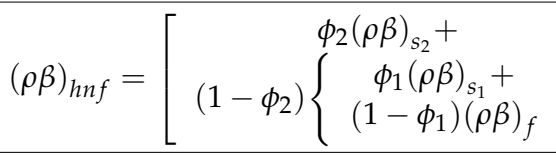 \\
\hline Heat capacitance & $\left(\rho c_{p}\right)_{h n f}=\left(1-\phi_{1}\right)\left(\rho c_{p}\right)_{f}+\phi_{1}\left(\rho c_{p}\right)_{s_{1}}$ & $\begin{array}{c}\left(\rho c_{p}\right)_{h n f}= \\
\phi_{2}\left(\rho c_{p}\right)_{s_{2}}+ \\
{\left[1-\phi_{2}\right)\left\{\begin{array}{c}\phi_{1}\left(\rho c_{p}\right)_{s_{1}}+ \\
\left(1-\phi_{1}\right)\left(\rho c_{p}\right)_{f}\end{array}\right\}}\end{array}$ \\
\hline
\end{tabular}
hybrid nanosuspension. Following Khan et al. [36], Devi and Devi [46], Rostami et al. [5] and Waini et al. [7], the chemophysical attributes for mono and hybrid nanosuspensions are provided in Table 1 .

Table 1. Chemo-physical attributes of hybrid nanosuspension $[2,5,36,46]$.

In Table 1, volume fractions of silica and molybdenum disulphide nanoparticles are indicated by $\varphi_{1}$ and $\varphi_{2}$, respectively where $\varphi_{1}=\varphi_{2}=0$ is meant to be the regular liquid. The hybrid nanosuspension includes 0.1 volume fraction of $\mathrm{SiO}_{2}$ (i.e., $\varphi_{1}$ ) and the concentration of $\mathrm{MoS}_{2}$ is changed from 0 to $0.1\left(0 \leq \phi_{2} \leq 0.1\right)$. Table 2 demonstrates the chemical attributes of the nanoadditives and the host liquid (see Maraj et al. [14], Rostami et al. [5], Ghadikolae et al. [15] and Khan et al. [16]). 
Table 2. Chemo-physical attributes of host liquid and nanoadditives [5,14-16].

\begin{tabular}{cccc}
\hline Properties & Water & $\mathbf{S i O}_{\mathbf{2}}$ & $\mathbf{M o S}_{\mathbf{2}}$ \\
\hline$c_{p}\left(\mathrm{~J} \cdot \mathrm{kg}^{-1} \cdot \mathrm{K}^{-1}\right)$ & 4179 & 730 & 397.746 \\
$\rho\left(\mathrm{kg} \cdot \mathrm{m}^{-3}\right)$ & 997.1 & 2650 & 5060 \\
$k\left(\mathrm{~W} \cdot \mathrm{m}^{-1} \cdot \mathrm{K}^{-1}\right)$ & 0.613 & 1.5 & 34.5 \\
$B \times 10^{-5}\left(\mathrm{~K}^{-1}\right)$ & 21.0 & 42.7 & 2.8242 \\
\hline
\end{tabular}

Meanwhile, Table 3 shows the different shape impacts on governing parameters. Further, the solid components of $\mathrm{SiO}_{2}$ and $\mathrm{MoS}_{2}$ are denoted by the subscripts $s_{1}$ and $s_{2}$, respectively. The subscripts $h n f, f$ and $n f$ and denotes hybrid nanoliquid, base liquid and nanoliquid respectively.

Table 3. Type of nanoadditives with their geometry parameter values [3].

\begin{tabular}{cc}
\hline Nanoparticles Type & Geometry Parameter \\
\hline Spherical & 3.0 \\
Bricks & 3.7 \\
Cylindrical & 4.9 \\
Platelets & 5.7 \\
Blade & 8.6 \\
\hline
\end{tabular}

Following non-similarity parameters as in Patil et al. [44,47], Rajakumar et al. [32] and Roy et al. [33] are employed. The non-similarity transformations and resulting flow variables are as follows:

$$
\left.\begin{array}{l}
\xi=\int_{0}^{x} \frac{U_{e}}{U_{\infty}}\left(\frac{r}{R}\right)^{2} d\left(\frac{x}{R}\right) \quad \eta=\left(\frac{R e}{2 \xi}\right)^{\frac{1}{2}}\left(\frac{U_{e}}{U_{\infty}}\right)\left(\frac{r}{R}\right) \frac{y}{R}, \quad F=f_{\eta}, \\
\psi(x, y)=U_{\infty} R\left(\frac{2 \xi}{R e}\right)^{\frac{1}{2}} f(\xi, \eta), u=\left(\frac{R}{r}\right) \frac{\partial \psi}{\partial y}, v=-\left(\frac{R}{r}\right) \frac{\partial \psi}{\partial x}, G=\frac{T-T_{\infty}}{T_{W}-T_{\infty}}
\end{array}\right\}
$$

In view of Equation (5), we have

$$
\begin{aligned}
& u=U_{e} F \\
& v=-\left(\frac{R}{r}\right) U_{\infty} R\left(\frac{2 \xi}{R e}\right)^{1 / 2}\left\{\frac{f}{2 \xi} \xi_{x}+\frac{3}{2 R} \sin ^{3}\left(\frac{x}{R}\right) f_{\xi}+\frac{2 \eta}{R} \cot \left(\frac{x}{R}\right) F-\frac{\eta \xi_{x} F}{2 \xi}\right\}
\end{aligned}
$$

Let

$$
a_{11}=\frac{\mu_{h n f}}{\mu_{f}}, a_{12}=\frac{\rho_{h n f}}{\rho_{f}}, a_{13}=\frac{(\rho \beta)_{h n f}}{(\rho \beta)_{f}}, a_{14}=\frac{k_{h n f}}{k_{f}}, a_{15}=\frac{\left(\rho c_{p}\right)_{h n f}}{\left(\rho c_{p}\right)_{f}}, a_{16}=\frac{a_{11}}{a_{12}}, a_{17}=\frac{a_{13}}{a_{11}},
$$

and

$$
a_{18}=\frac{a_{14}}{a_{15}}
$$

Now, utilizing the transformations (5), Equations (1)-(3) are reduced as below and Equation (1) is satisfied identically.

$$
\begin{gathered}
F_{\eta \eta}+\frac{\gamma(\xi)\left(1-F^{2}\right)}{a_{16}}+\frac{f F_{\eta}}{a_{16}}+\frac{2 \xi}{a_{16}}\left[F_{\eta} f_{\xi}-F F_{\xi}\right]+a_{17} R i \cdot m(\bar{x}) \cdot G=0 \\
G_{\eta \eta}+\frac{P r \cdot f G_{\eta}}{a_{18}}+\frac{2 P r \cdot \xi}{a_{18}}\left(G_{\eta} f_{\xi}-F G_{\xi}\right)=0
\end{gathered}
$$


The employed border conditions are given below:

$$
\left.\begin{array}{l}
\text { At } \eta=0: F(\xi, 0)=\frac{2}{3} \varepsilon \alpha \frac{\sin (n \bar{x})}{\sin (\bar{x})}, G(\xi, 0)=1, \\
\text { As } \eta \rightarrow \infty: F(\xi, \infty)=1, \quad G(\xi, \infty)=0 .
\end{array}\right\}
$$

The non-dimensional characteristics arising in this research are:

$$
\begin{aligned}
& R i=\frac{G r}{R e^{2}}, G r=\frac{g \beta_{f}\left(T_{w}-T_{\infty}\right) R^{3}}{v_{f}^{2}}, R e=\frac{U_{\infty} R}{v_{f}}, m(\bar{x})=\frac{8(1-\cos (\bar{x}))^{2}(2+\cos (\bar{x}))}{27 \sin ^{4}(\bar{x})}, \\
& \gamma(\xi)=\frac{2 \xi}{U_{e}} \frac{d U_{e}}{d \xi^{\prime}}, \varepsilon=\frac{U_{0}}{U_{\infty}}, \operatorname{Pr}=\frac{\mu_{f}\left(c_{p}\right)_{f}}{k_{f}}
\end{aligned}
$$

Furthermore, $f(\xi, \eta)=\int_{0}^{\eta} F d \eta+f_{w}$; where $f_{w}=0$ denotes an impermeable surface.

The velocity profile in the mainstream current is given below:

$$
\frac{U_{e}}{U_{\infty}}=\frac{3}{2} \sin (\bar{x}), \frac{r}{R}=\sin (\bar{x}), \bar{x}=\frac{x}{R}
$$

Therefore, $\xi$ and $\gamma(\xi)$ can be expressed in $\bar{x}$ as below:

$$
\xi=\frac{S_{1}^{2} S_{3}}{2}, \gamma(\bar{x})=\frac{2 \cos (\bar{x}) S_{3}}{3 S_{2}^{2}}
$$

where

$$
S_{1}=1-\cos (\bar{x}), S_{2}=1+\cos (\bar{x}), S_{3}=2+\cos (\bar{x})
$$

The above equations, that are expressed in terms of $\xi$, are rewritten in $\bar{x}$, using the following relation:

$$
\xi \frac{\partial}{\partial \xi}=B(\bar{x}) \frac{\partial}{\partial \bar{x}}
$$

where

$$
B(\bar{x})=\frac{\tan \left(\frac{\bar{x}}{2}\right) S_{3}}{3 S_{2}}
$$

In view of Equations (11) and (12), Equations (6) and (7) become as follows

$$
\begin{gathered}
F_{\eta \eta}+\frac{\gamma(\bar{x})\left(1-F^{2}\right)}{a_{16}}+\frac{f F_{\eta}}{a_{16}}+\frac{2 B(\bar{x})}{a_{16}}\left[F_{\eta} f_{\bar{x}}-F F_{\bar{x}}\right]+a_{17} R i \cdot m(\bar{x}) \cdot G=0 \\
G_{\eta \eta}+\frac{P r \cdot f G_{\eta}}{a_{18}}+\frac{2 P r \cdot B(\bar{x})}{a_{18}}\left(G_{\eta} f_{\bar{x}}-F G_{\bar{x}}\right)=0
\end{gathered}
$$

The relevant border constraints are

$$
\left.\begin{array}{ll}
\text { At } \eta=0: F(\bar{x}, 0)=\frac{2}{3} \varepsilon \alpha \frac{\sin (n \bar{x})}{\sin (\bar{x})}, & G(\bar{x}, 0)=1 \\
\text { As } \eta \rightarrow \infty: F(\bar{x}, \infty)=1, & G(\bar{x}, \infty)=0
\end{array}\right\}
$$

All parameters and non-dimensional characteristics that arise in the analysis are described in Nomenclature. The gradients at the sphere are:

surface drag parameter

$$
C_{f}=a_{11} \frac{9 \sin (\bar{x}) S_{2} S_{3}{ }^{-1 / 2} F_{\eta}(\bar{x}, 0)}{2 R e^{1 / 2}}, R e^{1 / 2} C_{f}=a_{11} \frac{9}{2} \sin (\bar{x}) S_{2} S_{3}{ }^{-1 / 2} F_{\eta}(\bar{x}, 0)
$$

and energy transport strength

$$
N u=-a_{14} \frac{3}{2} S_{2} S_{3}{ }^{-1 / 2} R e^{1 / 2} G_{\eta}(\bar{x}, 0), R e^{-1 / 2} N u=-a_{14} \frac{3}{2} S_{2} S_{3}{ }^{-1 / 2} G_{\eta}(\bar{x}, 0)
$$




\section{Method of Analysis}

Equations (13) and (14) are linearized employing the Quasilinearization method in the form:

$$
\begin{gathered}
F_{\eta \eta}{ }^{i+1}+A_{1}^{i} F_{\eta}^{i+1}+A_{2}^{i} F_{\bar{x}}^{i+1}+A_{3}^{i} F^{i+1}+A_{4}^{i} G^{i+1}=A_{5}^{i} \\
G_{\eta \eta}{ }^{i+1}+B_{1}^{i} G_{\eta}{ }^{i+1}+B_{2}^{i} G_{\bar{x}}^{i+1}+B_{3}^{i} F^{i+1}=B_{4}^{i}
\end{gathered}
$$

Here the parameters at the $(i+1)$ th iteration are found by using the known $i$ th iterative coefficients. The non-dimensional border conditions become

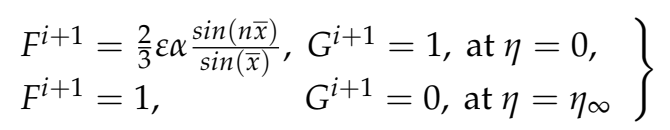

where boundary layer edge is denoted by $\eta_{\infty}$.

Parameters in Equations (18) and (19) are

$$
\begin{aligned}
& A_{1}^{i}=\frac{a_{12}}{a_{11}}\left(2 B(\bar{x}) f_{\bar{x}}+f\right), A_{2}^{i}=-\frac{a_{12}}{a_{11}} 2 B(\bar{x}) F, A_{3}^{i}=-\frac{a_{12}}{a_{11}}\left[2 B(\bar{x}) F_{\bar{x}}+2 \gamma(\bar{x}) F\right], \\
& A_{4}^{i}=\frac{a_{13}}{a_{11}} \operatorname{Ri} \cdot m(\bar{x}), A_{5}^{i}=-\frac{a_{12}}{a_{11}}\left(2 B(\bar{x}) F F_{\bar{x}}+\gamma(\bar{x})\left(F^{2}+1\right)\right), B_{1}^{i}=\frac{a_{15}}{a_{14}} \operatorname{Pr}\left(2 B(\bar{x}) f_{\bar{x}}+f\right), \\
& B_{2}^{i}=-2 \frac{a_{15}}{a_{14}} \operatorname{Pr} \cdot B(\bar{x}) F, B_{3}^{i}=-2 \frac{a_{15}}{a_{14}} \operatorname{Pr} \cdot B(\bar{x}) G_{\bar{x}}, B_{4}^{i}=-2 \frac{a_{15}}{a_{14}} \operatorname{Pr} \cdot B(\bar{x}) F G_{\bar{x}} .
\end{aligned}
$$

Numerical solutions to the Equations (18) and (19) with the border constraints (20) were worked out through implicit finite difference approximation, where the backward and central differences are employed. The obtained algebraic set is solved employing the Varga's algorithm [48]. The step size $\Delta \bar{x}=0.01$ is chosen along $\bar{x}$ direction and $\Delta \eta=0.01$ is chosen along $\eta$ direction. When the present and previous iterations difference is low than 0.0001 , the iteration process is stopped.

\section{Results and Discussion}

Molybdenum disulphide and silica/water combination of nanoparticles is taken for the present investigation. In the present model, 0.1 volume fraction of silica $\left(\varphi_{1}\right)$ is included to the host liquid $\left(\mathrm{H}_{2} \mathrm{O}\right)$ and accordingly molybdenum disulphide $\left(\varphi_{2}\right)$ is introduced with numerous concentrations to obtain $\mathrm{MoS}_{2}-\mathrm{SiO}_{2}$ /water hybrid nanosuspension. By considering the different combination of nanoparticles, the similar approach has been investigated by many researchers $[46,49,50]$. The surface roughness is modeled in terms of large frequency and low amplitude sinusoidal waves. The frequency characteristic $(n)$ and low variable $(\alpha)$ are employed for $5 \leq n \leq 100$ and $0 \leq \alpha \leq 0.3$. The smooth border is denoted using $\alpha=0$, whilst the rough border is denoted using $\alpha \neq 0$ [44,51]. As curvilinear $\bar{x}$ and $y$ coordinates are perpendicular one another, the angle between these coordinates is taken as $\pi / 2$. The magnitude $\varepsilon=0$ characterizes the no-slip condition at the border, i.e., smooth border. The empirical shape factor $s$ for nanoparticles is calculated using the formula $s=\psi / 3$, where $\psi$ is the sphericity. As per the Hamilton and Crosser approach [52], sphericity is the proportion of sphere area to the border area of physical particles with the same volumes. In the numerical computation, we have considered $\mathrm{Pr}=7$ that demonstrates the water as the host liquid, and it is constant throughout the investigation $[30,53]$.

Figure 2 exhibits the effect of combined convection characteristic $(R i)$ and velocity ratio characteristic $(\varepsilon)$ on velocity pattern $\{F(\bar{x}, \eta)\}$. Rising values of combined parameter boost the nanosuspension velocity. Enhancing magnitudes of combined convection parameter specify higher significant impact of forced convection. Thus, the velocity of the fluid augments with the forced convection. In addition, in existence of rough surface $(\alpha=0.1)$, velocity slip is noticed close to the surface. That is, abrupt jump arises close to sphere with roughness. Moreover, the characteristic $(\varepsilon)$ is determined as the ratio between the slip velocity and the ambient circulation velocity. Thus, as the velocity ratio characteristic $(\varepsilon)$ augments, the velocity of the liquid is enhanced. 


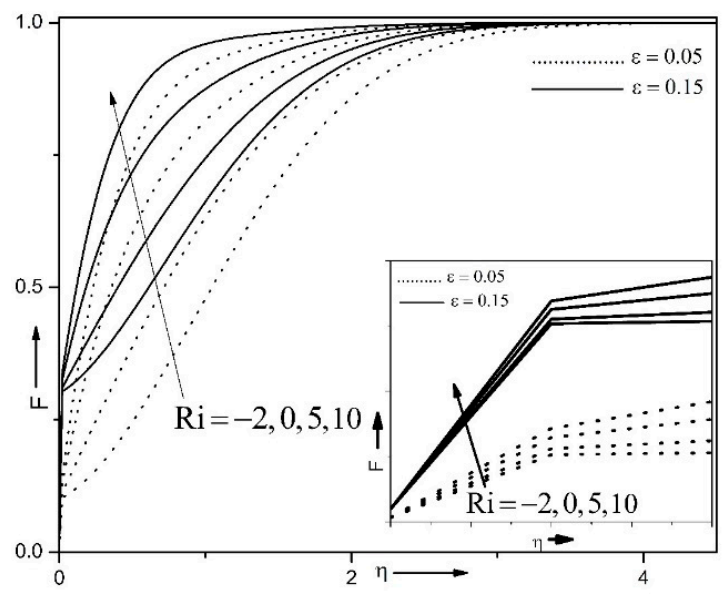

Figure 2. Impact of combined convection characteristic $(R i)$ and velocity ratio characteristic $(\varepsilon)$ on $\{F(\bar{x}, \eta)\}$ when $\bar{x}=1.5, \varphi_{1}=0.1, \varphi_{2}=0.1, n=10$ and $\alpha=0.1$.

Figure 3 displays the impact of combined convection parameter $(R i)$ and volume fraction $\left(\varphi_{2}\right)$ on temperature distribution $\{G(\bar{x}, \eta)\}$. For enhancing values of combined convection characteristic, the temperature of the liquid diminishes. The difference between the wall temperature and ambient flow temperature increases, for increasing values of $R i$, which reduces the fluid temperature. Further, for escalating magnitude of volume fraction $\left(\varphi_{2}\right)$, the temperature of the liquid augments. The liquid heat conductivity enhances for enhancing magnitude of volume fraction $\left(\varphi_{2}\right)$ and rises the capacity of the hybrid nanofluid to conduct more heat, which enhances the temperature of the liquid.

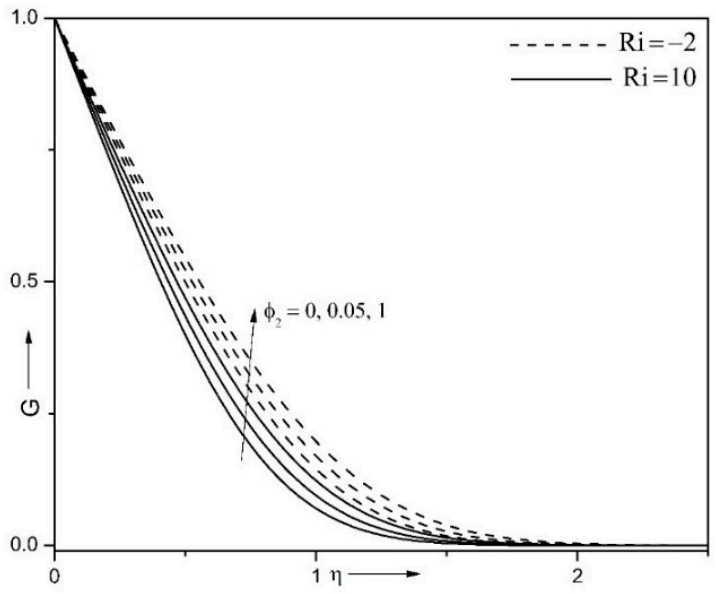

Figure 3. Impact of combined convection characteristic $(R i)$ and volume fraction $\left(\varphi_{2}\right)$ on $\{G(\bar{x}, \eta)\}$ when $\bar{x}=0.5, \varphi_{1}=0.1, \varepsilon=0.15, n=10$ and $\alpha=0.1$.

Figure 4 displays the impact of velocity ratio characteristic $(\varepsilon)$ and volume fraction $\left(\varphi_{2}\right)$ on velocity profile $\{F(\bar{x}, \eta)\}$. For enhancing magnitudes of concentration $\left(\varphi_{2}\right)$ the velocity of the liquid diminishes. It is clear that the velocity of the fluid is larger in absence of nanoparticles compared its presence, for each corresponding value of $\varepsilon$. For increasing values of $\varphi_{2}$ the hybrid nanofluid becomes denser and concentrated. Moreover, velocity of the fluid enhances with enhancing values of velocity ratio characteristic. This is caused because the larger value of velocity ratio characteristic indicates more slip at the border that raises the liquid velocity. 


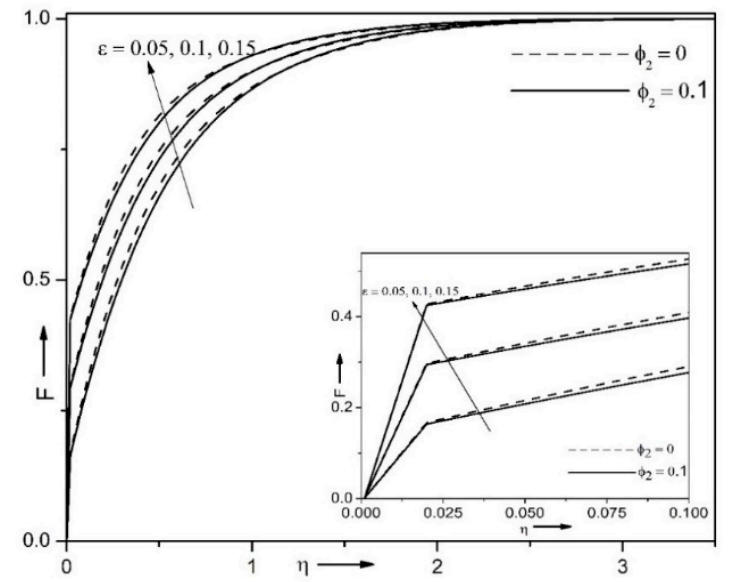

Figure 4. Influence of velocity ratio characteristic $(\varepsilon)$ and volume fraction $\left(\varphi_{2}\right)$ on $\{F(\bar{x}, \eta)\}$ when $\bar{x}=1.5, \varphi_{1}=0.1, \varepsilon=0.15, n=10$ and $\alpha=0.1$.

Figure 5 presents the impact of small parameter $(\alpha)$ and volume fraction $\left(\varphi_{2}\right)$ on temperature profile $\{G(\bar{x}, \eta)\}$. Temperature of the liquid diminishes with enhance in this small parameter. As we seen that the fluid temperature diminishes more in rough surface $(\alpha \neq 0)$ case compared to smooth surface $(\alpha=0)$. Such phenomenon can be explained by the packets of fluid that are captured in the troughs formed owing to the surface roughness. It experiences slip at the wall of the sphere, when the liquid flows about the rough sphere and this enhances the velocity of the liquid. The growth of the liquid velocity yields more fluid movement across the wall of the sphere and this diminishes the liquid's temperature. In addition, the liquid's temperature enhances with rise in the volume fraction $\left(\varphi_{2}\right)$. It is very clear that hybrid nanofluid has greater thermal conductivity than that of base fluid. Physically, it means that the nanoparticles with high thermal conductivity allow intensifying the heat transference and an inclusion of such nanoparticles enhances energy transport with a rise of the temperature.

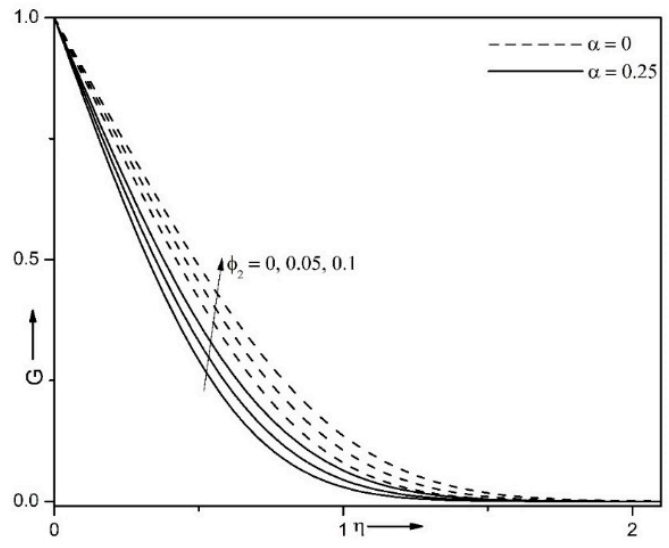

Figure 5. Impact of small parameter $(\alpha)$ and volume fraction of $\left(\varphi_{2}\right)$ on $\{G(\bar{x}, \eta)\}$ when $\bar{x}=0.5$, $R i=10, \varepsilon=0.15, n=10$ and $\varphi_{1}=0.1$.

Figures 6 and 7 portray the impact of combined convection characteristics $(R i)$ and volume fraction $\left(\varphi_{2}\right)$ on surface drag coefficient $\left(\operatorname{Re}^{1 / 2} C_{f}\right)$ and energy transport strength $\left(\operatorname{Re}^{-1 / 2} N u\right)$. Surface drag coefficient and energy transport strength are enhanced for rising values of combined convection characteristic. The positive magnitudes of $R i$ illustrate the essential impact of free convection over the forced one. Thus, the buoyancy force inside the liquid intensifies the liquid motion and as a result it augments frictions at the surface. In addition, the drop between the border temperature and free stream temperature enhances 
for rising values of $R i$, which increases the energy transport strength from wall to fluid. Further, for enhancing values of volume fraction $\left(\varphi_{2}\right)$, the friction at the surface and the energy transport strength enhance. This is because addition of nanoparticles in the host liquid leads to intensifying its temperature and as a result one can find an intensification of the energy transport.

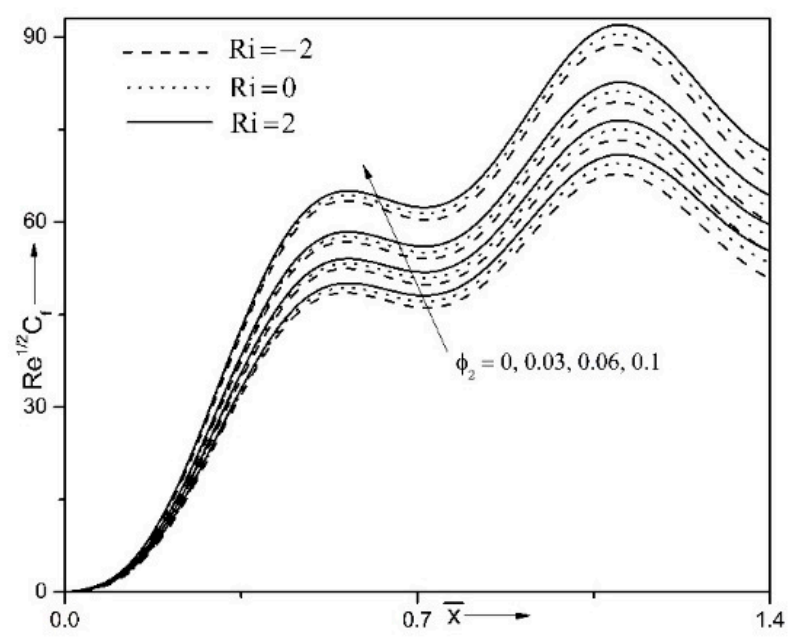

Figure 6. Impact of combined convection characteristic $(R i)$ and volume fraction $\left(\varphi_{2}\right)$ on $\left(\operatorname{Re}^{1 / 2} C_{f}\right)$ when $\varphi_{1}=0.1, \varepsilon=0.15, n=10$ and $\alpha=0.1$.

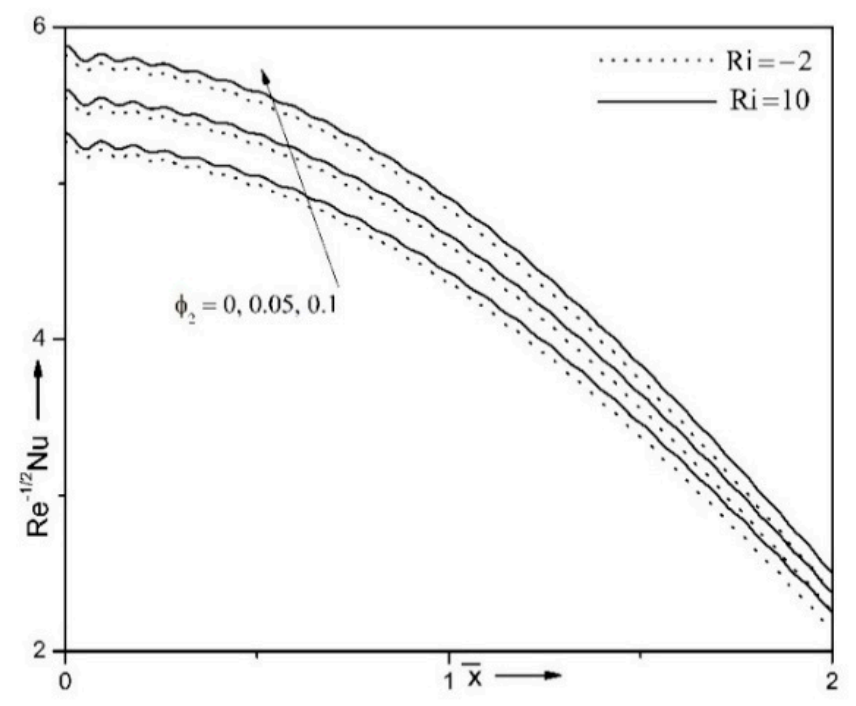

Figure 7. Impact of combined convection characteristic $(R i)$ and volume fraction $\left(\varphi_{2}\right)$ on $\left(\operatorname{Re}^{-1 / 2} N u\right)$ for $\varphi_{1}=0.1, \varepsilon=0.15, n=10$ and $\alpha=0.3$.

Figure 8 portrays the influence of small parameter $(\alpha)$ and volume fraction $\left(\varphi_{2}\right)$ on energy transport strength $\left(\operatorname{Re}^{-1 / 2} N u\right)$. The energy transport strength boosts with enhancing nanoparticle volume fraction $\left(\varphi_{2}\right)$. The physical reason is that these nanoparticles which are characterized by large heat conductivity display the augmentation of the energy transport coefficient because this parameter is directly proportional to heat conductivity. Further, heat transfer rate enhances with enhance in the small parameter. The sinusoidal waves are observed in presence of surface roughness. This is because the sphere has more area owing to the presence of roughness and thereby intensifies the heat transfer in a larger quantity from the sphere into the ambient fluid. 


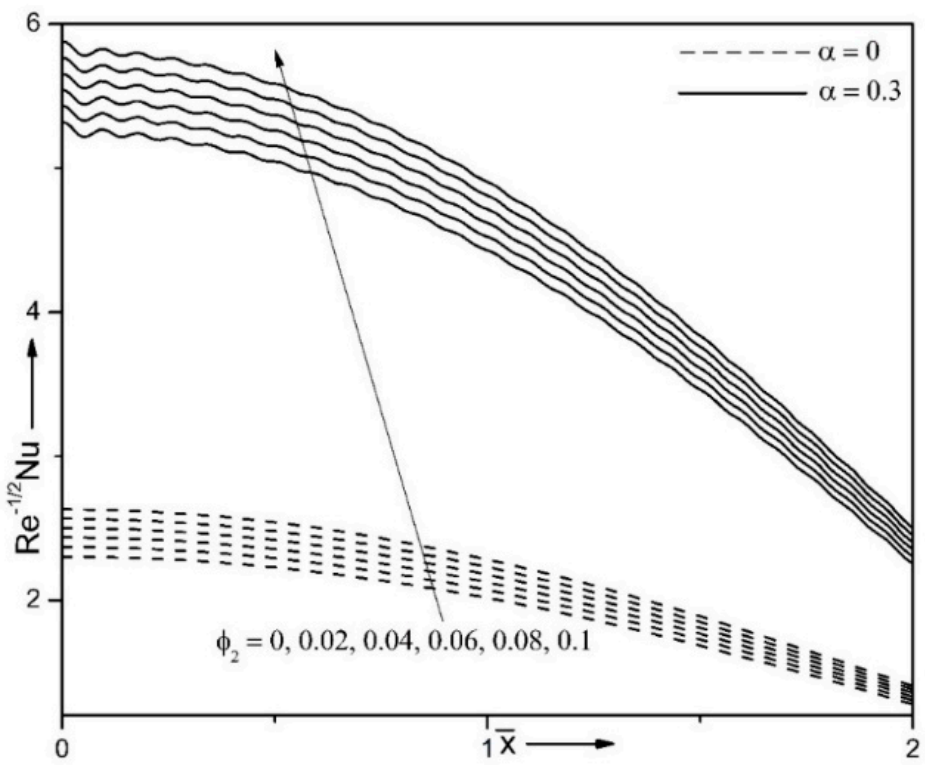

Figure 8. Impact of small parameter $(\alpha)$ and volume fraction $\left(\varphi_{2}\right)$ on $\left(\operatorname{Re}^{-1 / 2} N u\right)$ for $R i=10, \varepsilon=0.15$, $n=10$ and $\varphi_{1}=0.1$.

Figures 9 and 10 show the comparison of hybrid nanofluid $\left(\mathrm{MoS}_{2}-\mathrm{SiO}_{2} / \mathrm{H}_{2} \mathrm{O}\right)$, mono nanofluid $\left(\mathrm{SiO}_{2} / \mathrm{H}_{2} \mathrm{O}\right)$ and base liquid $\left(\mathrm{H}_{2} \mathrm{O}\right)$ with various values of small parameter $(\alpha)$ for the surface drag coefficient $\left(\operatorname{Re}^{1 / 2} C_{f}\right)$ and energy transport strength $\left(\operatorname{Re}^{-1 / 2} N u\right)$. Energy transport strength and coefficient of friction at the border are enhanced for hybrid nanosuspension compared to mono nanofluid and regular liquid. In addition, the friction and rate of heat transfer high for rough surface $(\alpha \neq 0)$ case compared to smooth surface $(\alpha=0)$ and sinusoidal waves are seen in presence of rough surface $(\alpha \neq 0)$. Hence, we can conclude that the hybrid nanofluid has more thermal conductivity than that of nanofluid and base fluid due to the rising magnitudes of nanoparticles concentration fundamentally designate the quicker heat transmission from surface of the cylinder to ambient fluid, this boosts the thermal conductivity and consequently temperature of hybrid nanofluid, which causes the intensive enhance in the magnitudes of temperature profile and rate of heat transfer coefficient, significantly.

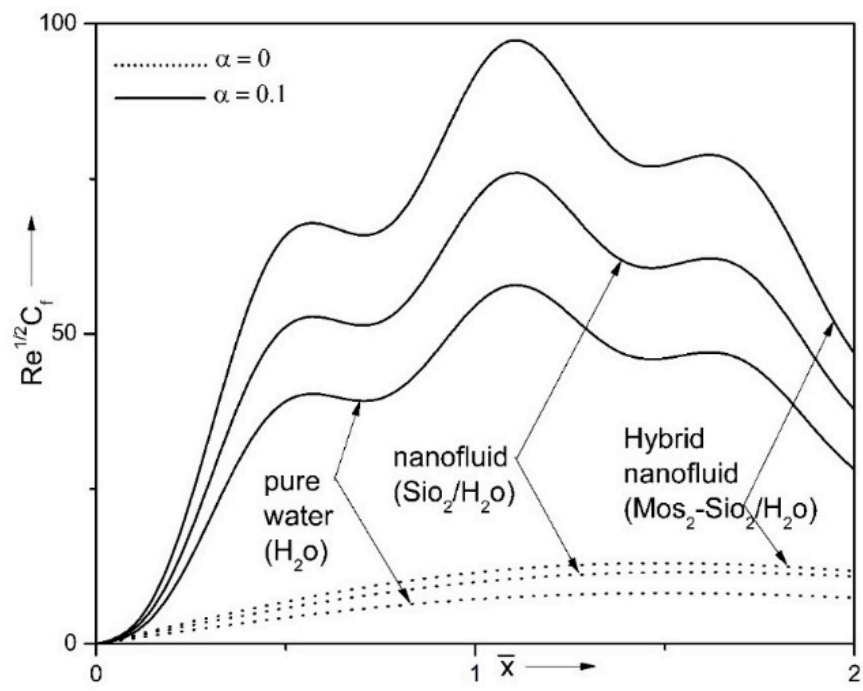

Figure 9. Impact of small parameter $(\alpha)$ on $\left(\operatorname{Re}^{1 / 2} C_{f}\right)$ when $R i=10, \varepsilon=0.15$ and $n=10$. 


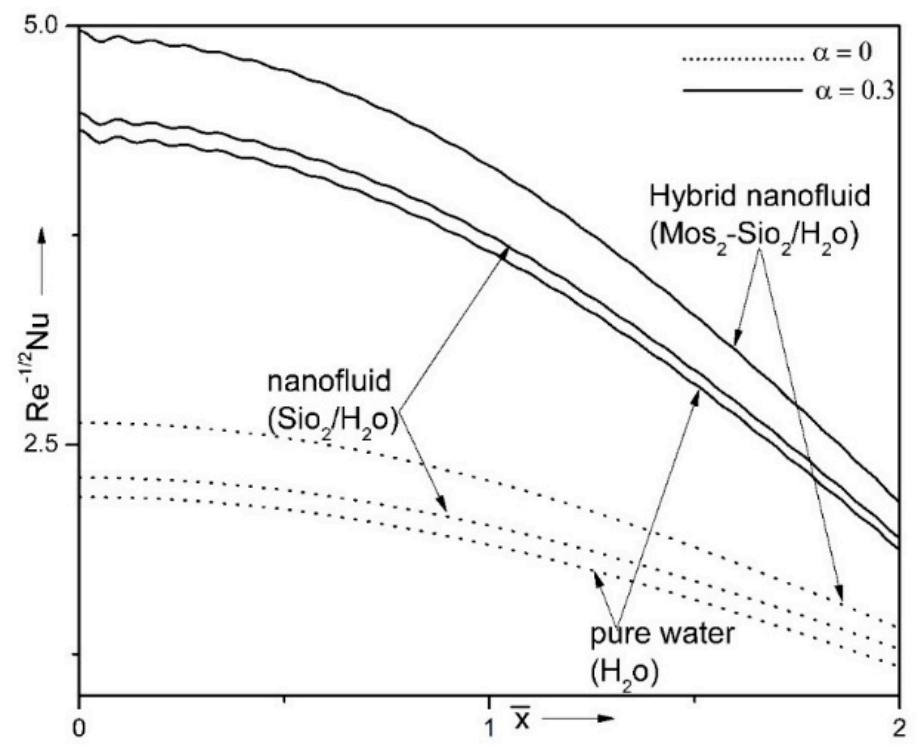

Figure 10. Impact of small parameter $(\alpha)$ on $\left(\operatorname{Re}^{-1 / 2} N u\right)$ when $R i=10, \varepsilon=0.15$ and $n=10$.

Figures 11 and 12 exhibit the impact of $\alpha$ and $n$ on surface drag parameter $\left(\operatorname{Re}^{1 / 2} C_{f}\right)$ and energy transport strength $\left(\operatorname{Re}^{-1 / 2} N u\right)$. Coefficient of friction at the surface and the Nusselt number are enhanced for enhancing values of frequency parameter and non-zero values of small parameter $(\alpha \neq 0)$. It is highlighted that, for regardless magnitudes of frequency coefficient the lines merge all together in smooth surface $(\alpha=0)$ case. The sinusoidal variations are observed in rough surface $(\alpha \neq 0)$ case. The amplitude of the sinusoidal waves enhances with intensifying values of small parameter, while the number of sinusoidal variations enhances as rise in $n$. Hence, the roughness of the surface has an essential influence on the liquid motion in comparison to the smooth surface. In addition, at $\bar{x}=0.5$ and $n=100$, the friction at the surface enhances about $55 \%$, when $\alpha$ varies from 0.1 to 0.3 .

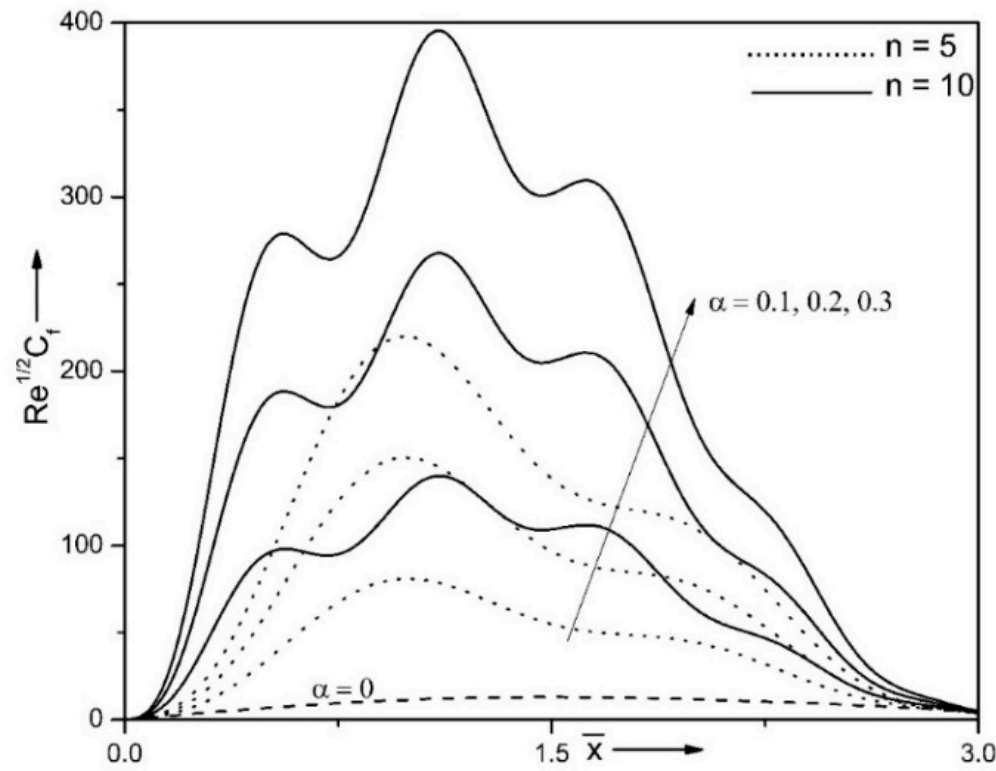

Figure 11. Impact of $\alpha$ and $n$ on $\left(\operatorname{Re}^{1 / 2} C_{f}\right)$ when $\varphi_{1}=0.1, \varphi_{2}=0.1, R i=10, \varepsilon=0.15$. 


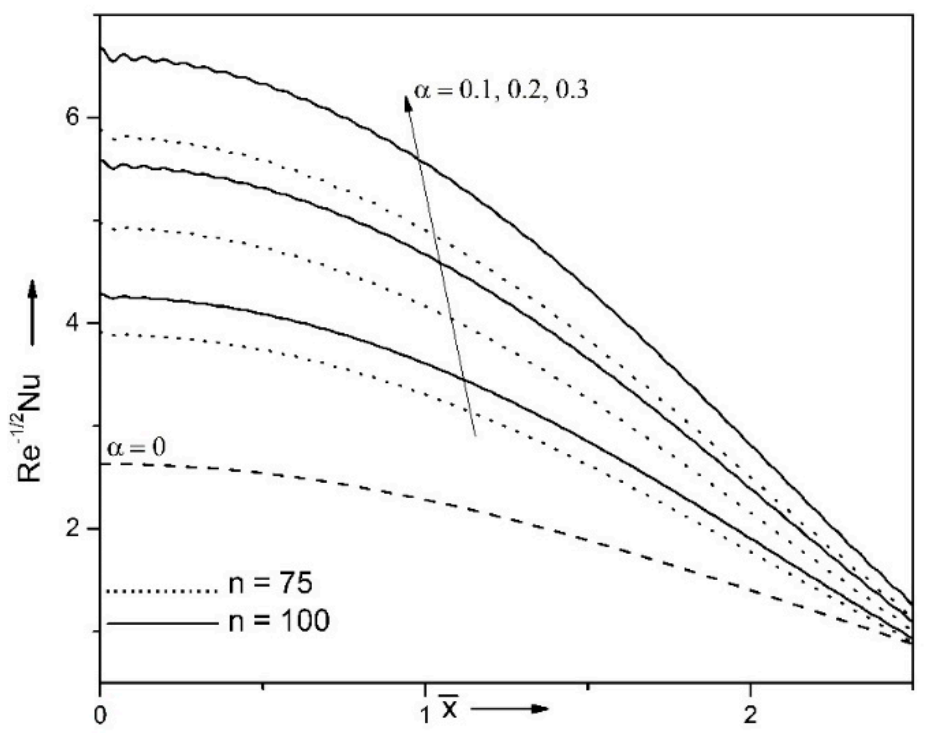

Figure 12. Impact of $\alpha$ and $n$ on $\left(\operatorname{Re}^{-1 / 2} N u\right)$ when $\varphi_{1}=0.1, \varphi_{2}=0.1, R i=10, \varepsilon=0.15$.

Figures 13 and 14 explain the influence of shape factor with various values of small parameter on temperature profile $\{G(\bar{x}, \eta)\}$ and energy transport strength $\left(\operatorname{Re}^{-1 / 2} N u\right)$. The graphical results reveal that, for all considered shapes such as, spherical, bricks, cylindrical, platelets and blade, there is an overall enhance in the values of $\{G(\bar{x}, \eta)\}$ and $\left(\operatorname{Re}^{-1 / 2} N u\right)$. Particle shape has an essential influence on the heat exchange performance. Their impact can be observed in the chemo-physical attributes of the hybrid nanosuspension. Among the considered shapes, blade-shaped particles give the high heat performance compared to the platelets, cylindrical and bricks, and sphere-shaped particles give the low heat performance. Further, enhancing values of small parameter, the temperature profile lessens, while Nusselt number augments. Physically, addition of nanoparticles in the regular liquid leads to the temperature growth, so an intensification of the Nusselt number is quite obvious. For instance, at $\bar{x}=0.5$ the heat transfer rate enhances about $16 \%$, from spherical to blade shaped nanoparticles type in presence of rough surface.

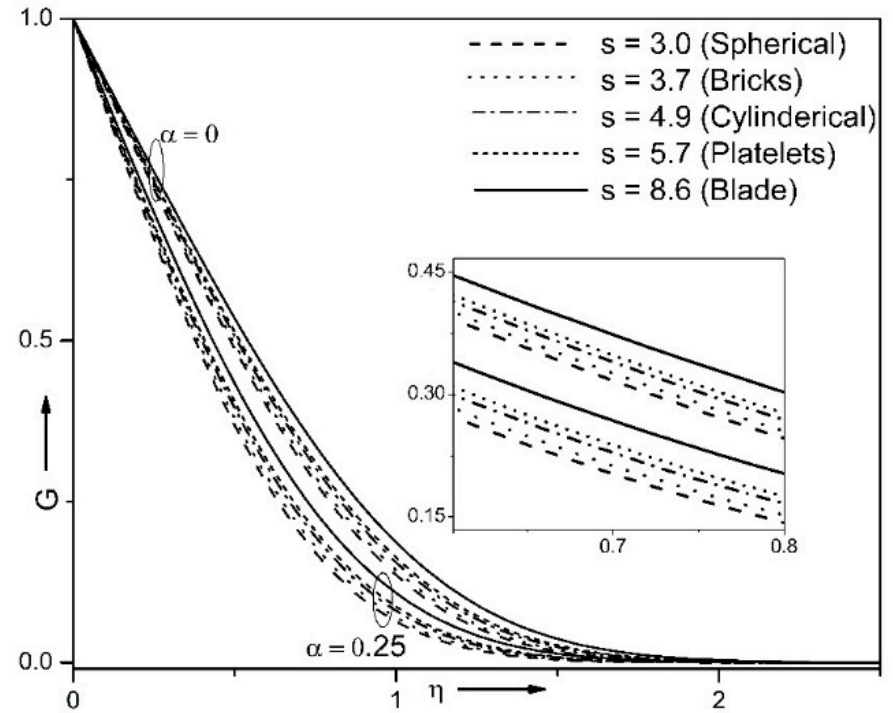

Figure 13. Impact of shape factor on $\{G(\bar{x}, \eta)\}$ when $\varphi_{1}=0.1, \varphi_{2}=0.1, R i=10, n=10, \alpha=0.3, \bar{x}=0.5$, $\varepsilon=0.15$. 


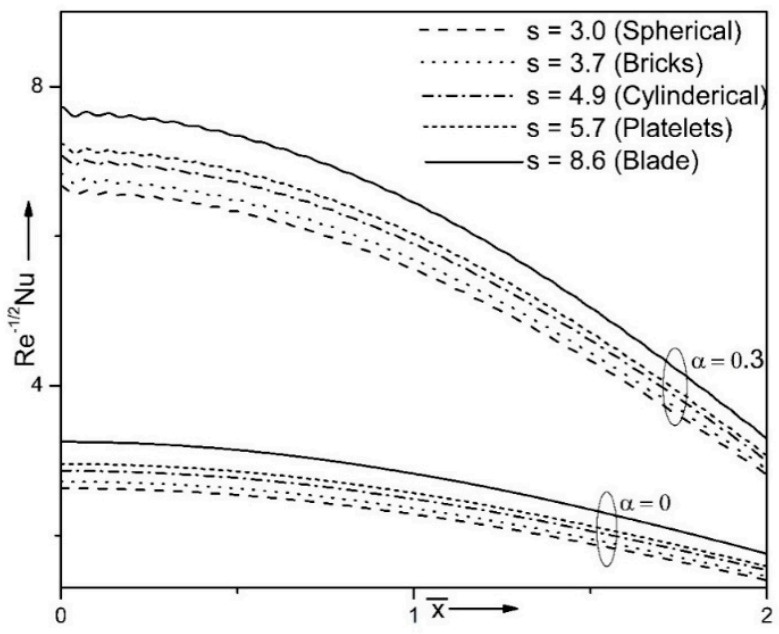

Figure 14. Impact of shape factor on $\left(\operatorname{Re}^{-1 / 2} N u\right)$ when $\varphi_{1}=0.1, \varphi_{2}=0.1, R i=10, n=10, \varepsilon=0.15$.

Taking into account an influence of the considered shapes of nanoparticles on velocity profiles (see Figure 15) it is possible to highlight that the blade-shaped particles give the highest growth of the velocity in comparison with other studied shapes, and sphericalshaped particles illustrate the formation of the smallest velocity. Further, a rise of small parameter reflects a growth of the velocity profile.

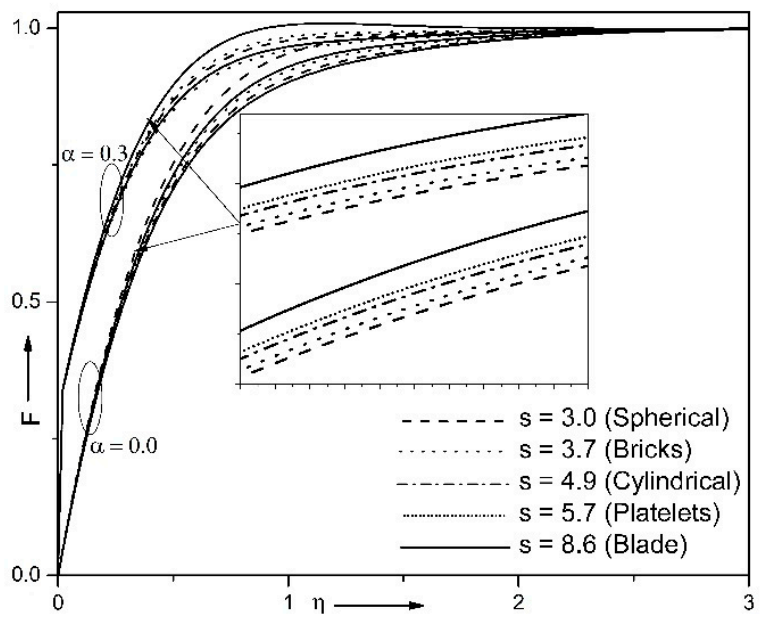

Figure 15. Impact of shape factor on $\{F(\bar{x}, \eta)\}$ when $\varphi_{1}=0.1, \varphi_{2}=0.1, R i=10, n=10, \bar{x}=0.5$, $\varepsilon=0.15$.

Figure 16 explains the impact of non-similarity parameter and combined convection parameter on velocity distribution $\{F(\bar{x}, \eta)\}$ and temperature distribution $\{G(\bar{x}, \eta)\}$. Velocity profile reduces while, temperature profile boosts in absence of non-similarity variable in opposing buoyancy flow case. Further, opposite outcomes are observed in presence of non-similarity parameter in assisting buoyancy motion case. Reason is that $\bar{x}$ directs as a favorable pressure drop. Intensifying magnitudes of combined convection coefficient augments the velocity distribution while, reduces the temperature distribution. It is clear from figure that the velocity of liquid is more pronounced for larger $R i$ in assisting motion variant. Physically, more buoyancy force is generated for greater values of $R i$, which gave the maximum energy to the moving fluid, and such heat creates the confrontation in the circulation. The opposing model was scrutinized for the velocity in opposing flow version. In addition, it ascertains that the temperature and thermal boundary layer are diminished owing to $R i$ in the considered circulations. 


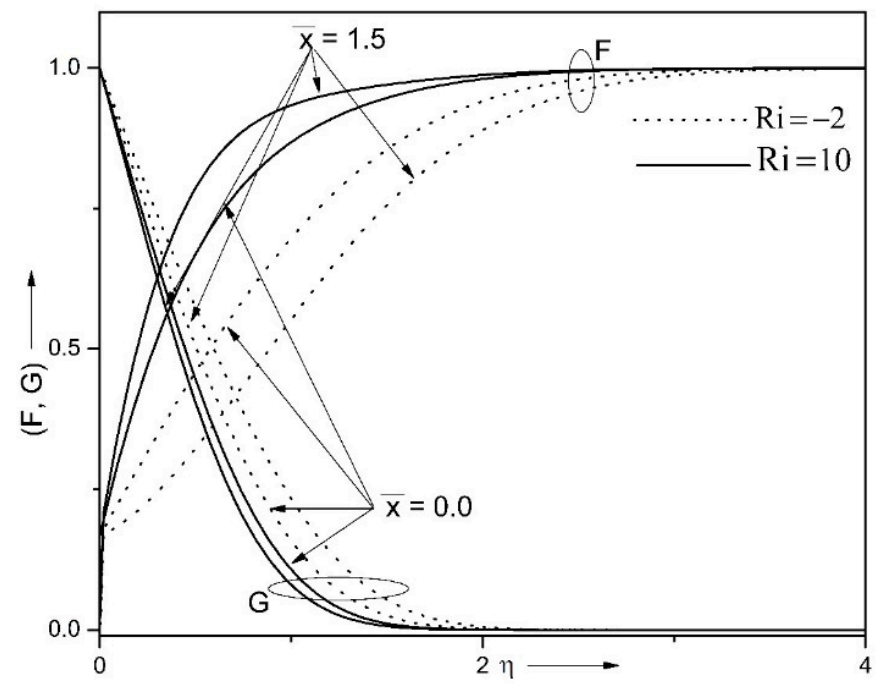

Figure 16. Impact of non-similarity variable $(\bar{x})$ and combined convection parameter $(R i)$ on $\{F(\bar{x}, \eta)\}$ and $\{G(\bar{x}, \eta)\}$ when $\varphi_{1}=0.1, \varphi_{2}=0.1, \alpha=0.25, n=10, \varepsilon=0.1$.

To verify the accuracy of the computational approach, the obtained outcomes found for several values of $\mathrm{Ri}$, by setting all characteristics values to zero except $\mathrm{Pr}=0.7$ are compared with the outcomes of Rajakumar et al. [32] in Figure 17 and it is obtained that the outcomes are well agreed.

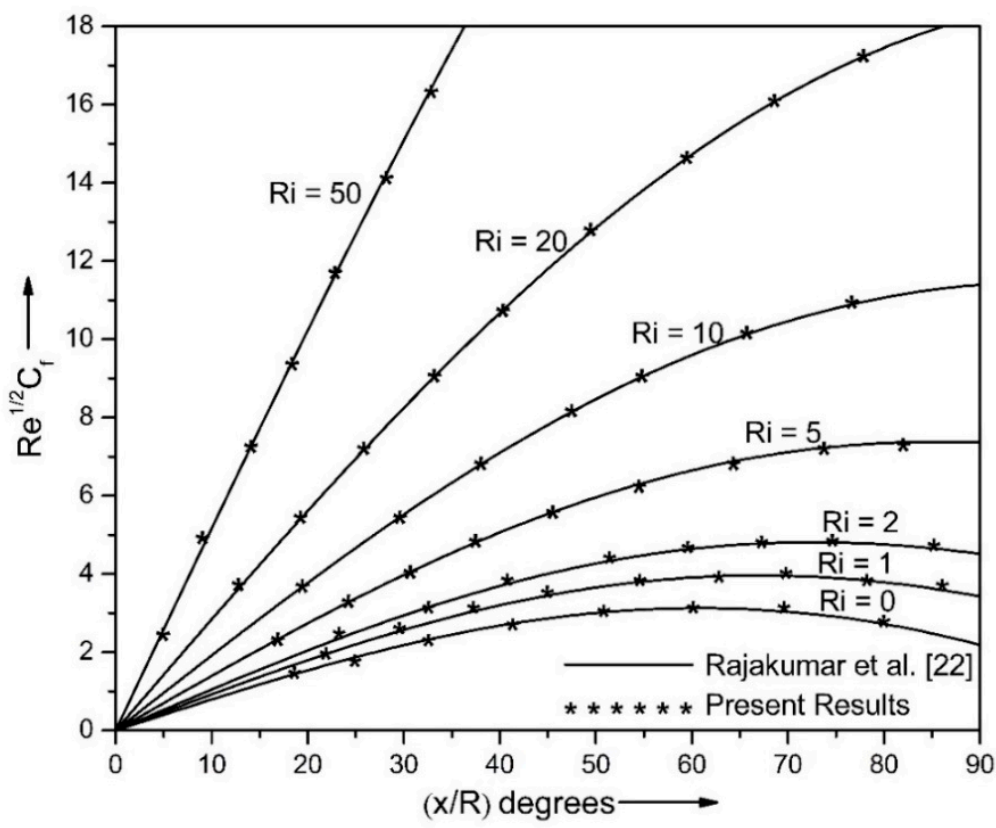

Figure 17. Angular patterns of the skin friction parameter for $\mathrm{Pr}=0.7$ compared to outcomes of Rajakumar et al. [32] obtained by choosing all parameter values to zero.

Table 4 shows the influence of different values of combined convection parameter for mono nanofluid and hybrid nanofluid for skin-friction coefficient and energy transport strength. A rise of $R i$ reflects an increase in heat transport strength and friction at the surface for both the mono nanofluid and hybrid nanofluid. In addition, it is clear that, the hybrid nanofluid values are comparatively larger than that of nanofluid, for skin-friction coefficient as well as energy transport strength in smooth surface case. In addition, it is seen that the same trend is observed in rough surface case. 
Table 4. Comparison of hybrid nanofluid $\left(\varphi_{1}=0.1\right.$ and $\left.\varphi_{2}=0.1\right)$ and mono nanofluid $\left(\varphi_{1}=0.1\right.$ and $\left.\varphi_{2}=0.0\right)$ for different magnitudes of combined convection coefficient (Ri) at smooth and rough surfaces, for skin-friction coefficient and energy transport strength when $\bar{x}=0.5, n=10, \varepsilon=0.1$.

\begin{tabular}{|c|c|c|c|c|c|}
\hline \multirow{2}{*}{$\begin{array}{c}\text { Combined } \\
\text { Convection } \\
\text { Parameter }(R i)\end{array}$} & & \multicolumn{2}{|c|}{$\begin{array}{c}\text { Mono Nanofluid } \\
\left(\varphi_{1}=0.1 \text { and } \varphi_{2}=0.0\right)\end{array}$} & \multicolumn{2}{|c|}{$\begin{array}{c}\text { Hybrid Nanofluid } \\
\left(\varphi_{1}=0.1 \text { and } \varphi_{2}=0.1\right)\end{array}$} \\
\hline & & $R e^{1 / 2} C_{\mathrm{f}}$ & $R e^{-1 / 2} N u$ & $R e^{1 / 2} C_{f}$ & $R e^{-1 / 2} N u$ \\
\hline$R i=-2$ & \multirow{5}{*}{$\begin{array}{l}\text { smooth } \\
\text { surface } \\
(\alpha=0)\end{array}$} & 1.91924 & 1.73737 & 2.76707 & 2.07747 \\
\hline$R i=0$ & & 2.68659 & 1.85759 & 3.54184 & 2.18376 \\
\hline$R i=3$ & & 3.71230 & 1.99284 & 4.60356 & 2.30996 \\
\hline$R i=6$ & & 4.64655 & 2.10531 & 5.58725 & 2.41753 \\
\hline$R i=10$ & & 5.79680 & 2.22851 & 6.81020 & 2.54115 \\
\hline$R i=-2$ & \multirow{5}{*}{$\begin{array}{c}\text { rough } \\
\text { surface } \\
(\alpha=0.25)\end{array}$} & 115.67549 & 2.11400 & 150.75397 & 2.46100 \\
\hline$R i=0$ & & 116.33356 & 2.19692 & 151.43079 & 2.53750 \\
\hline$R i=3$ & & 117.24895 & 2.30142 & 152.38640 & 2.63768 \\
\hline$R i=6$ & & 118.10291 & 2.39003 & 153.28743 & 2.72483 \\
\hline$R i=10$ & & 119.17278 & 2.49174 & 154.42511 & 2.82653 \\
\hline
\end{tabular}

Table 5 demonstrates the comparison with previous published data illustrating a very good agreement. It presents the values of heat transfer rate against $\bar{x}$ and $R i$. The negative magnitudes of mixed convection coefficient $(R i<0)$ indicate the opposing buoyant flow, while $R i>0$ is for assisting buoyant flow. From Table 5, it is clear that Nusselt number is a reducing relation of $\bar{x}$.

Table 5. Comparison values of energy transport strength $\left(R e^{-1 / 2} N u\right)$ with published outcomes for different magnitudes of $\bar{x}$ and $R i$ for $\operatorname{Pr}=0.7$.

\begin{tabular}{cccccccccc}
\hline & \multicolumn{3}{c}{ Nazar et al. [54] } & \multicolumn{3}{c}{ Mohamed et al. [55] } & \multicolumn{3}{c}{ Present Results } \\
\hline$\overline{\boldsymbol{x}}$ & $\boldsymbol{R} \boldsymbol{i}=-\mathbf{1}$ & $\boldsymbol{R} \boldsymbol{i = 0}$ & $\boldsymbol{R} \boldsymbol{i = 1}$ & $\boldsymbol{R} \boldsymbol{i = - \mathbf { 1 }}$ & $\boldsymbol{R} \boldsymbol{i = 0}$ & $\boldsymbol{R} \boldsymbol{i = 1}$ & $\boldsymbol{R} \boldsymbol{i = - \mathbf { 1 }}$ & $\boldsymbol{R} \boldsymbol{i = 0}$ & $\boldsymbol{R} \boldsymbol{i = 1}$ \\
\hline $0^{0}$ & 0.7870 & 0.8162 & 0.8463 & 0.7858 & 0.8150 & 0.8406 & 0.7918 & 0.8180 & 0.8426 \\
\hline $10^{0}$ & 0.7818 & 0.8112 & 0.8371 & 0.7809 & 0.8103 & 0.8362 & 0.7778 & 0.8139 & 0.8385 \\
\hline $20^{0}$ & 0.7669 & 0.7974 & 0.8239 & 0.7615 & 0.7967 & 0.8232 & 0.7729 & 0.8008 & 0.8254 \\
\hline $30^{0}$ & 0.7422 & 0.7746 & 0.8024 & 0.7719 & 0.7741 & 0.8018 & 0.7497 & 0.7792 & 0.8054 \\
\hline $40^{0}$ & 0.7076 & 0.7429 & 0.7725 & 0.7074 & 0.7425 & 0.7721 & 0.7134 & 0.7475 & 0.7737 \\
\hline $50^{0}$ & 0.6624 & 0.7022 & 0.7345 & 0.6624 & 0.7032 & 0.7354 & 0.6754 & 0.7081 & 0.7377 \\
\hline
\end{tabular}

\section{Conclusions}

The current investigation explores the combined convective flow of silica-molybdenum disulphide/water nanosuspension over a rough sphere. The influences of varying small parameter, mixed convection, concentration of nanoadditives and frequency characteristic on the non-dimensional velocity and temperature distributions, surface drag coefficient and energy transport strength are investigated and explained with the help of different graphs. From the detailed analysis of the obtained results, the following vital observations are made:

- $\quad$ the hybrid nanofluid augments the temperature, as well as Nusselt number at the wall;

- velocity distribution is reduced, while friction at the surface enhances in the case of hybrid nanofluid;

- $\quad$ slip exists near the surface of the sphere owing to roughness, which yields steep jump in the liquid velocity close to the border; 
- for enhancing magnitudes of small parameter, the friction at the surface and the Nusselt number are enhanced;

- $\quad$ skin-friction parameter and the Nusselt number are boosted for hybrid nanoliquid on comparison with mono nanofluid and the base fluid;

- $\quad$ skin-friction parameter and the Nusselt number have the highest values for bladeshaped nanoadditives and lowest value is found for spherical-formed nanoparticles.

Author Contributions: Conceptualization, P.M.P. and H.F.S.; methodology, P.M.P. and H.F.S.; software, H.F.S.; validation, H.F.S.; investigation, P.M.P., H.F.S. and M.A.S.; writing-original draft preparation, P.M.P., H.F.S. and M.A.S.; writing-review and editing, P.M.P., H.F.S. and M.A.S. All authors have read and agreed to the published version of the manuscript.

Funding: This work is supported under the grant with No. F. 16-6/(DEC. 2018)/2019(NET/CSIR)940 dated 24-07-2019 by University Grant's Commission, New-Delhi.

Institutional Review Board Statement: Not applicable.

Informed Consent Statement: Not applicable.

Data Availability Statement: The data presented in this study are available in this paper.

Conflicts of Interest: The authors declare no conflict of interest.

\section{Abbreviations}

F dimensionless velocity

$\mathrm{Nu} \quad$ Nusselt number

G non-dimensional temperature

$g \quad$ gravity acceleration

$n$ frequency parameter

$v \quad y$-velocity projection

$r(x) \quad$ radius of the section normal to axis of the sphere

Pr Prandtl number

$U_{0} \quad$ reference velocity

$f \quad$ dimensionless stream function

$R \quad$ radius of the sphere

$T_{w} \quad$ temperature at the wall

Re Reynolds number

Gr Grashof number

$\mathrm{Ri} \quad$ combined convection parameter

$T$ temperature

$T_{\infty} \quad$ ambient temperature

u $\quad x$-velocity projection

$U_{\infty} \quad$ free stream velocity constant

$x, y \quad$ Cartesian coordinates

$U_{e} \quad$ free stream velocity

$\alpha \quad$ small parameter

$\Delta \bar{x}, \Delta \eta \quad$ step size in $\bar{x}$ and $\eta$ directions

$\varepsilon \quad$ velocity ratio parameter

$\bar{x}, \eta \quad$ transformed variables

$v_{f} \quad$ kinematic viscosity

$\varphi_{1} \quad$ volume fraction of silica nanoparticle

$\varphi_{2} \quad$ volume fraction of molybdenum disulphide nanoparticle

$\psi \quad$ dimensionless stream function

$f \quad$ base fluid

hnf hybrid nanofluid

nf mono nanofluid

s1 solid component for silica

s2 solid component for molybdenum disulphide

$\bar{x}, \eta \quad$ variables of the partial derivatives 


\section{References}

1. Buongiorno, J. Convective transport in nanofluids. J. Heat Transf. 2006, 128, 240-250. [CrossRef]

2. Tiwari, R.K.; Das, M.K. Heat transfer augmentation in a two-sided lid-driven differentially heated square cavity utilizing nanofluids. Int. J. Heat Mass Transf. 2007, 250, 2002-2018. [CrossRef]

3. Choi, S.U.S. Enhancing thermal conductivity of fluids with nanoparticles. In Proceedings of the 1995 ASME International Mechanical Engineering Congress and Exposition (FED 231/MD), San Francisco, CA, USA, 12-17 November 1995; Volume 6, pp. 99-105.

4. Chu, Y.-M.; Nisar, K.S.; Khan, U.; Kasmaei, H.D.; Malaver, M.; Zaib, A.; Khan, I. Mixed convection in MHD water-based molybdenum disulfide-graphene oxide hybrid nanofluid through an upright cylinder with shape factor. Water 2020, 12, 1723. [CrossRef]

5. Rostami, M.N.; Dinarvand, S.; Pop, I. Dual solutions for mixed convective stagnation-point flow of an aqueous silica-alumina hybrid nanofluid. Chin. J. Phys. 2018, 56, 2465-2478. [CrossRef]

6. Chamkha, A.J.; Miroshnichenko, I.V.; Sheremet, M.A. Numerical analysis of unsteady conjugate natural convection of hybrid water-based nanofluid in a semicircular cavity. J. Therm. Sci. Eng. Appl. 2017, 9, 041004. [CrossRef]

7. Waini, I.; Ishak, A.; Pop, I. Mixed convection flow over an exponentially stretching/shrinking vertical surface in a hybrid nanofluid. Alex. Eng. J. 2020, 59, 1881-1891. [CrossRef]

8. Dinarvand, S.; Rostami, M.N.; Pop, I. A novel hybridity model for TiO2-CuO/water hybrid nanofluid flow over a static/moving wedge or corner. Sci. Rep. 2019, 9, 16290. [CrossRef]

9. Acharya, N.; Das, K.; Kundu, P.K. Ramification of variable thickness on $\mathrm{MHD} \mathrm{TiO}_{2}$ and Ag nanofluid flow over a slandering stretching sheet using NDM. Eur. Phys. J. Plus 2016, 131, 303. [CrossRef]

10. Tlili, I.; Nabwey, H.A.; Samrat, S.P.; Sandeep, N. 3D MHD nonlinear radiative flow of CuO-MgO/methanol hybrid nanofluid beyond an irregular dimension surface with slip effect. Sci. Rep. 2020, 10, 9181. [CrossRef]

11. Aladdin, N.A.L.; Bachok, N.; Pop, I. Cu- $\mathrm{Al}_{2} \mathrm{O}_{3} /$ water hybrid nanofluid flow over a permeable moving surface in presence of hydromagnetic and suction effects. Alex. Eng. J. 2020, 59, 657-666. [CrossRef]

12. Izadi, M.; Mohebbi, R.; Karimi, D.; Sheremet, M.A. Numerical simulation of natural convection heat transfer inside a $\perp$ shaped cavity filled by a MWCNT- $\mathrm{Fe}_{3} \mathrm{O}_{4}$ / water hybrid nanofluids using LBM. Chem. Eng. Process. Process Intensif. 2018, 125, 56-66. [CrossRef]

13. Tassaddiq, A.; Khan, S.; Bilal, M.; Gul, T.; Mukhtar, S.; Shah, Z.; Bonyah, E. Heat and mass transfer together with hybrid nanofluid flow over a rotating disk. AIP Adv. 2020, 10, 055317. [CrossRef]

14. Maraj, E.N.; Iqbal, Z.; Azhar, E.; Mehmood, Z. A comprehensive shape factor analysis using transportation of $\mathrm{MoS}_{2}-\mathrm{SiO} 2 / \mathrm{H}_{2} \mathrm{O}$ inside an isothermal semi vertical inverted cone with porous boundary. Results Phys. 2018, 8, 633-641. [CrossRef]

15. Ghadikolaei, S.S.; Gholinia, M.; Hoseini, M.E.; Ganji, D.D. Natural convection MHD flow due to $\mathrm{MoS}_{2}-\mathrm{Ag}$ nanoparticles suspended in $\mathrm{C}_{2} \mathrm{H}_{6} \mathrm{O}_{2}-\mathrm{H}_{2} \mathrm{O}$ hybrid base fluid with thermal radiation. J. Taiwan Inst. Chem. Eng. 2019, 97, 12-23. [CrossRef]

16. Khan, U.; Shafiq, A.; Ziab, A.; Baleanu, D. Hybrid nanofluid on mixed convective radiative flow from an irregular variably thick moving surface with convex and concave effects. Case Stud. Therm. Eng. 2020, 21, 100660. [CrossRef]

17. Saqid, M.; Ali, F.; Khan, I.; Ahmed Sheikh, N.; Bin Shafie, S. Convection in ethylene glycol-based molybdenum disulfide nanofluid. J. Therm. Anal. Calorim. 2019, 135, 523-532.

18. Raza Shah, T.; Muhammad, A.; Mansoor Janjua, M. On aqua-based Silica $\left(\mathrm{SiO}_{2}-\right.$ Water $)$ nanocoolant: Convective thermal potential and experimental precision evaluation in aluminum tube radiator. Nanomaterials 2020, 10, 1736. [CrossRef] [PubMed]

19. Wang, H.; Yu, L.; Lee, Y.H.; Shi, Y.; Hsu, A.; Chin, M.L.; Li, L.J.; Dubey, M.; Kong, J.; Palacios, T. Integrated circuits based on bilayer $\mathrm{MoS}_{2}$ transistors. Nano Lett. 2012, 12, 4674-4680. [CrossRef] [PubMed]

20. Das, S.; Chen, H.Y.; Penumatcha, A.V.; Appenzeller, J. High performance multilayer $\mathrm{MoS}_{2}$ transistors with scandium contacts. Nano Lett. 2012, 13, 100-105. [CrossRef]

21. Radisavljevic, B.; Radenovic, A.; Brivio, J.; Giacometti, I.V.; Kis, A. Single-layer MoS 2 transistors. Nat. Nanotechnol. 2011, 6, 147-150. [CrossRef]

22. Castellanos-Gomez, A.; Poot, M.; Steele, G.A.; Van der Zant, H.S.; Agrait, N.; Rubio-Bollinger, G. Mechanical properties of freely suspended semiconducting graphene-like layers based on $\mathrm{MoS}_{2}$. Nanoscale Res. Lett. 2012, 7, 233. [CrossRef] [PubMed]

23. Winer, W.O. Molybdenum disulfide as a lubricant: A review of the fundamental knowledge. Wear 1967, 10, 422-452. [CrossRef]

24. Kato, H.; Takama, M.; Iwai, Y.; Washida, K.; Sasaki, Y. Wear and mechanical properties of sintered copper-tin composites containing graphite or molybdenum disulfide. Wear 2003, 255, 573-578. [CrossRef]

25. Carlisle, E.M.; Hawthorne, M.F.; Dunks, G.B. Silicon: An Essential Element for the Chick. Science 1972, 178, 619-621. [CrossRef]

26. Shafie, S.; Gul, A.; Khan, I. Molybdenum disulfide nanoparticles suspended in water-based nanofluids with mixed convection and flow inside a channel filled with saturated porous medium. AIP Conf. Proc. 2016, 1775, 030042-030048.

27. Bejan, A. Convection Heat Transfer; John Wiley and Sons: New York, NY, USA, 2013.

28. Weigand, B.; Crawford, M.; Kays, W.M. Convective Heat and Mass Transfer, 4th ed.; McGraw Hill Education: New York, NY, USA, 2017.

29. Shenoy, A.; Sheremet, M.; Pop, I. Convective Flow and Heat Transfer from Wavy Surfaces: Viscous Fluids, Porous Media and Nanofluids; CRC Press: New York, NY, USA, 2016.

30. Salleh, M.Z.; Nazar, R.; Pop, I. Mixed convection boundary layer flow about a solid sphere with Newtonian heating. Arch. Mech. 2010, 62, 283-303. 
31. Rashad, A.M.; Chamkha, A.J.; El-Kabir, S.M.M. Effects of chemical reaction on heat and mass transfer by mixed convection flow about a sphere in a saturated porous media. Int. J. Numer. Methods Heat Fluid Flow 2011, 21, 418-433. [CrossRef]

32. Rajakumar, J.; Saikrishnan, P.; Chamkha, A. Non-uniform mass transfer in MHD mixed convection flow of water over a sphere with variable viscosity and Prandtl number. Int. J. Numer. Methods Heat Fluid Flow 2016, 26, 2235-2251. [CrossRef]

33. Roy, S.; Saikrishnan, P.; Pandey, B.D. Influence of double slot suction (injection) into water boundary layer flows over sphere. Int. Commun. Heat Mass Transf. 2009, 36, 646-650. [CrossRef]

34. Waini, I.; Ishak, A.; Grosan, T.; Pop, I. Mixed convection of a hybrid nanofluid flow along a vertical surface embedded in a porous medium. Int. Commun. Heat Mass Transf. 2020, 114, 104565. [CrossRef]

35. Muhammad, K.; Hayat, T.; Alsaedi, A.; Dinarvand, B.; Momani, S. Mixed convective slip flow of hybrid nanofluid (MWCNTs $+\mathrm{Cu}+$ Water), nanofluid (MWCNTs + Water) and base fluid (Water): A comparative investigation. J. Therm. Anal. Calorim. 2020. [CrossRef]

36. Bognar, G.; Klazly, M.; Hriczo, K. Nanofluid flow past a stretching plate. Processes 2020, 8, 827. [CrossRef]

37. Bognar, G.; Hriczo, K. Similarity transformation approach for a heated ferrofluid flow in presence of magnetic field. Electron. J. Qual. Theory Differ. Equ. 2018, 42, 1-15. [CrossRef]

38. Khan, U.; Zaib, A.; Khan, I.; Baleanu, D.; Nisar, K.S. Enhanced heat transfer in moderately ionized liquid due to hybrid $\mathrm{MoS}_{2} / \mathrm{SiO}_{2}$ nanofluids exposed by nonlinear radiation: Stability analysis. Crystals 2020, 10, 142. [CrossRef]

39. Khan, U.; Zaib, A.; Mebarek-Oudina, F. Mixed convective magneto flow of $\mathrm{SiO}_{2}-\mathrm{MoS}_{2} / \mathrm{C}_{2} \mathrm{H}_{6} \mathrm{O}_{2}$ hybrid nanoliquids through a vertical stretching/shrinking wedge: Stability analysis. Arab. J. Sci. Eng. 2020, 45, 9061-9073. [CrossRef]

40. Nikuradse, J. Stromungsgesetze in rauhen Rohren; VDI-Verlag: Berlin, Germany, 1933.

41. Owen, P.R.; Thompson, W.R. Heat transfer across rough surfaces. J. Fluid Mech. 1963, 15, 321-324. [CrossRef]

42. Dawson, D.A.; Trass, O. Mass transfer at rough surfaces. Int. J. Heat Mass Transf. 1972, 15, 1317-1336. [CrossRef]

43. Sedahmed, G.H.; Shemilt, L.W. Forced convection mass transfer at rough surfaces annuli. Lett. Heat Mass Transf. 1972, 3, 499-512. [CrossRef]

44. Patil, P.M.; Shashikant, A.; Hiremath, P.S.; Roy, S. Study of liquid oxygen and hydrogen diffusive flow past a sphere with rough surface. Int. J. Hydrogen Energy 2019, 44, 26624-26636. [CrossRef]

45. Patil, P.M.; Kulkarni, M.; Hiremath, P.S. Nonlinear mixed convective nanofluid flow along moving vertical rough plate. Rev. Mex. Física 2020, 66, 153-161. [CrossRef]

46. Devi, S.P.A.; Devi, S.S.U. Numerical investigation of hydromagnetic hybrid $\mathrm{Cu}-\mathrm{Al}_{2} \mathrm{O}_{3} /$ water nanofluid flow over a permeable stretching sheet with suction. Int. J. Nonlinear Sci. Numer. Simul. 2016, 17, 249-257. [CrossRef]

47. Patil, P.M.; Shankar, H.F.; Hiremath, P.S.; Momoniat, E. Nonlinear mixed convective nanofluid flow about a rough sphere with the diffusion of liquid hydrogen. Alex. Eng. J. 2021, 60, 1043-1053. [CrossRef]

48. Varga, R.S. Matrix Iterative Analysis; Prentice-Hall: Englewood Cliffs, NJ, USA, 2000.

49. Hayat, T.; Nadeem, S.; Khan, A.U. Rotating flow of Ag-CuO/ $\mathrm{H}_{2} \mathrm{O}$ hybrid nanofluid with radiation and partial slip boundary effects. Eur. Phys. J. E 2018, 41, 75. [CrossRef] [PubMed]

50. Yousefi, M.; Dinarvand, S.; Yazdi, M.E.; Pop, I. Stagnation-point flow of an aqueous titania-copper hybrid nanofluid toward a wavy cylinder. Int. J. Numer. Methods Heat Fluid Flow 2018, 28, 1716-1735. [CrossRef]

51. Patil, P.M.; Kulkarni, M.; Hiremath, P.S. Effects of surface roughness on mixed convective nanofluid flow past an exponentially stretching permeable surface. Chin. J. Phys. 2020, 64, 203-218. [CrossRef]

52. Hamilton, R.; Crosser, O. Thermal conductivity of heterogeneous two-component systems. Ind. Eng. Chem. Fundam. 1962, 1, 187-191. [CrossRef]

53. Patil, P.M.; Doddagoudar, S.H.; Hiremath, P.S. Impacts of surface roughness on mixed convection nanofluid flow with liquid hydrogen/nitrogen diffusion. Int. J. Numer. Methods Heat Fluid Flow 2019, 29, 2146-2174. [CrossRef]

54. Nazar, R.; Amin, N.; Pop, I. Mixed convection boundary layer flow about an isothermal sphere in a micropolar fluid. Int. J. Therm. Sci. 2003, 42, 283-293. [CrossRef]

55. Mohamed, M.K.A.; Sarif, N.M.; Noar, N.A.Z.M.; Salleh, M.Z.; Ishak, A. Viscous dissipation effect on the mixed convection boundary layer flow towards solid sphere. Trans. Sci. Technol. 2016, 3, 59-67. 